\title{
What is the Evidence for the Effectiveness of Scapulothoracic Strengthening Exercises in Individuals with Neck Pain: A Systematic Review
}

\author{
Anna-Maria Zacharakis \\ The University of South Australia, zacay002@mymail.unisa.edu.au \\ Lauren Mia Zanelli \\ The University of South Australia, zanlm002@mymail.unisa.edu.au \\ Holly Rose Watkins \\ The University of South Australia, wathr002@mymail.unisa.edu.au \\ Lea Victoria O'Brien \\ The University of South Australia, obrlv001@mymail.unisa.edu.au \\ Evan James Wolfendale \\ The University of South Australia, wolej001@mymail.unisa.edu.au \\ See next page for additional authors
}

Follow this and additional works at: https://nsuworks.nova.edu/ijahsp

Part of the Physiotherapy Commons

\section{Recommended Citation}

Zacharakis A, Zanelli LM, Watkins HR, O'Brien LV, Wolfendale EJ, White GH, et al. What is the Evidence for the Effectiveness of Scapulothoracic Strengthening Exercises in Individuals with Neck Pain: A Systematic Review. The Internet Journal of Allied Health Sciences and Practice. 2020 Jan 01;18(3), Article 11.

This Systematic Review is brought to you for free and open access by the College of Health Care Sciences at NSUWorks. It has been accepted for inclusion in Internet Journal of Allied Health Sciences and Practice by an authorized editor of NSUWorks. For more information, please contact nsuworks@nova.edu. 


\title{
What is the Evidence for the Effectiveness of Scapulothoracic Strengthening Exercises in Individuals with Neck Pain: A Systematic Review
}

\begin{abstract}
Neck pain is a highly prevalent issue, ranked as the fourth greatest issue worldwide in terms of overall disease burden, and consequently, places a substantial impact upon the healthcare system. Scapulothoracic exercises appear as a promising avenue for the treatment of neck pain amongst the various treatment options currently available. However, there is uncertainty surrounding the effectiveness and clinical application of this approach. Purpose: The aim of this review was to establish the evidence surrounding the clinical application and effectiveness of scapulothoracic strengthening exercises to reduce neck pain. Methods: A systematic search of four electronic databases, including Ovid Medline, Scopus, Ovid Embase and The Cochrane Library was conducted by two independent reviewers (EW, GW). Studies of adult participants who were receiving scapulothoracic strengthening exercises to reduce neck pain and improve functioning were included. Inclusion criteria were set to exclude participants with neck pain related to headaches or as a result of surgery, trauma, physiological abnormalities or neurological conditions. A total of 2,665 articles were evaluated for inclusion in this systematic review, with 39 included in a full-text screen and five included in the final review. Methodological quality was evaluated by three independent reviewers (AZ, HW, LO) using the PEDro critical appraisal tool and the National Health and Medical Research Council (NHMRC) hierarchy of evidence was used to determine included studies. Results: Five randomised controlled trials, encompassing a total of 329 participants, were included in this systematic review. Four of the studies investigated strength training for the non-painful scapulothoracic muscles, and one study included exercises targeting the painful upper trapezius muscle. Scapulothoracic intervention duration ranged from 20-90 minutes, with a varying frequency of 3-5 times per week. All five studies demonstrated some improvements in neck pain, with two included studies revealing short-term positive influences on activities of daily living and the neck disability index. One study showed significant improvements in neck range of motion and similarly, maximal voluntary contraction of cervical musculature improved in another study. Overall, analysis of the five included studies provided evidence that scapulothoracic strength exercises may be effective in alleviating neck pain. Conclusion: A limited number of studies have investigated the effect of scapulothoracic strengthening exercises as a primary modality in the treatment of neck pain. Scapulothoracic strengthening exercises could be considered in the treatment of neck pain, although the evidence is variable. Scapulothoracic strength training may have positive impacts across subjective and objective parameters including pain, and sequentially, activities of daily living, neck range of motion, and strength. However, the current literature base is limited by considerable diversity in intervention and outcome measures, and limited long-term follow up.
\end{abstract}

Author Bio(s)

Anna-Maria Zacharakis, BPhysio.

Lauren Zanelli, BPhysio.

Holly Watkins, BPhysio.

Lea O'Brien, BPhysio.

Evan Wolfendale, BPhysio.

George White, BPhysio.

Matt Ransom, BPhysio, MAdvClinPhysio(Sports), Academic researcher at the International Centre for Allied Health Evidence (iCAHE) and clinical supervisor in the School of Health Sciences, University of South 
Australia, Adelaide.

Authors

Anna-Maria Zacharakis, Lauren Mia Zanelli, Holly Rose Watkins, Lea Victoria O'Brien, Evan James Wolfendale, George Harry White, and Matt Ransom 


\title{
IIJAHSP \\ The Internet Joumnal of Allied Health Sciences and Practice
}

Dedicated to allied health professional practice and education

Vol. 18 No. 3 ISSN 1540-580X

\section{What is the Evidence for the Effectiveness of Scapulothoracic Strengthening Exercises in Individuals with Neck Pain? A Systematic Review}

\author{
Anna-Maria Zacharakis \\ Lauren Mia Zanelli \\ Holly Rose Watkins \\ Lea Victoria O'Brien \\ Evan James Wolfendale \\ George Harry White \\ Matt Ransom \\ University of South Australia \\ Australia
}

\begin{abstract}
Neck pain is a highly prevalent issue, ranked as the fourth greatest issue worldwide in terms of overall disease burden, and consequently, places a substantial impact upon the healthcare system. Scapulothoracic exercises appear as a promising avenue for the treatment of neck pain amongst the various treatment options currently available. However, there is uncertainty surrounding the effectiveness and clinical application of this approach. Purpose: The aim of this review was to establish the evidence surrounding the clinical application and effectiveness of scapulothoracic strengthening exercises to reduce neck pain. Methods: A systematic search of four electronic databases, including Ovid Medline, Scopus, Ovid Embase and The Cochrane Library was conducted by two independent reviewers (EW, GW). Studies of adult participants who were receiving scapulothoracic strengthening exercises to reduce neck pain and improve functioning were included. Inclusion criteria were set to exclude participants with neck pain related to headaches or as a result of surgery, trauma, physiological abnormalities or neurological conditions. A total of 2,665 articles were evaluated for inclusion in this systematic review, with 39 included in a full-text screen and five included in the final review. Methodological quality was evaluated by three independent reviewers (AZ, HW, LO) using the PEDro critical appraisal tool and the National Health and Medical Research Council (NHMRC) hierarchy of evidence was used to determine included studies. Results: Five randomised controlled trials, encompassing a total of 329 participants, were included in this systematic review. Four of the studies investigated strength training for the non-painful scapulothoracic muscles, and one study included exercises targeting the painful upper trapezius muscle. Scapulothoracic intervention duration ranged from 20-90 minutes, with a varying frequency of 3-5 times per week. All five studies demonstrated some improvements in neck pain, with two included studies revealing short-term positive influences on activities of daily living and the neck disability index. One study showed significant improvements in neck range of motion and similarly, maximal voluntary contraction of cervical musculature improved in another study. Overall, analysis of the five included studies provided evidence that scapulothoracic strength exercises may be effective in alleviating neck pain. Conclusion: A limited number of studies have investigated the effect of scapulothoracic strengthening exercises as a primary modality in the treatment of neck pain. Scapulothoracic strengthening exercises could be considered in the treatment of neck pain, although the evidence is variable. Scapulothoracic strength training may have positive impacts across subjective and objective parameters including pain, and sequentially, activities of daily living, neck range of motion, and strength. However, the current literature base is limited by considerable diversity in intervention and outcome measures, and limited long-term follow up.
\end{abstract}

Key Words: neck pain, scapulothoracic, resistance training, exercise therapy, treatment outcome, range of motion. 


\section{BACKGROUND}

Neck pain is a highly prevalent issue, ranked as the fourth greatest issue worldwide in terms of overall disease burden, and consequently places a substantial economic impact upon the healthcare system. ${ }^{1}$ Associated disability arising from neck pain not only poses a significant impact on the individual, but has flow on effects to their families and the greater community in which they live. ${ }^{1}$ Numerous factors have been attributed to the prevalence of neck pain with environmental factors such as desk-based work presenting individuals with a higher risk. ${ }^{2}$ The global point prevalence of neck pain in 2010 was estimated as $4.9 \%$ with subsequent translation to health-care referrals. ${ }^{3}$ Hence, there is a drive amongst clinicians to date, to determine the most effective and efficient strategies, which may be used in the management of neck pain.

There are numerous treatment options available to clinicians for the management of neck pain; these include posture correction, manipulation, and stretching exercises. ${ }^{4}$ Research has revealed correlations between exercises targeting muscle strength in regions such as the lower limbs or lower back, and reduction in back pain. ${ }^{5}$ However, uncertainty remains as to whether resistancebased exercises targeting the superficial musculature of the upper-back region i.e. "scapulothoracic exercises" will alleviate neck pain in the same way. ${ }^{6}$ It has been proposed that strengthening exercises may reduce pain through mechanisms similar to aerobic exercise -- exercise induced hypoalgesia. ${ }^{7}$ Uncertainty remains regarding the true mechanisms operational within such recovery, however, a commonly accepted hypothesis is that exercise may stimulate central opioid systems, as well as increase endorphin concentration. $^{7}$

Scapulothoracic exercises tailored to improve patterns of muscular activation in individuals with neck pain is an additional hypothesis proposed by Falla and colleagues. Adapted motor patterns of activation are thought to minimise activation of muscles responsible for pain or compensate for inhibited muscles. ${ }^{8}$ Wegner and colleagues note that any changes to axioscapular muscle activity may either exacerbate or contribute to neck pain. ${ }^{9}$ Such alterations may adversely impact mechanical stimuli influencing pain sensitive structures. ${ }^{9}$ It is proposed that strength training may reduce such muscle activation abnormalities, and hence improve pain. However, uncertainty remains regarding the degree to which muscle activation patterns contribute to the causation as well as the reduction of pain. ${ }^{10}$

The use of scapulothoracic strengthening exercises appear as a promising avenue in the treatment of neck pain. However, a gap remains in the literature regarding how scapulothoracic exercises are applied in clinical practice and their effectiveness in addressing neck pain and functioning.

The aim of this review was to investigate the clinical application and evidence for the effectiveness of scapulothoracic strengthening exercises in individuals with neck pain.

\section{METHODS}

This review protocol is registered with PROSPERO (registration number: CRD42019133294).

\section{Eligibility Criteria \\ Types of Studies}

Randomised controlled trials (RCTs) were sought as the primary source of evidence. Searches were limited to the English language and human subjects only, and all publication periods were included.

\section{Types of Participants}

Adults ( $\geq 18$ years old) of any gender or background, with either chronic or acute presentations of neck pain were included in this review. The review excluded participants with neck pain related to headaches or as a result of surgery, trauma, physiological abnormalities, or neurological conditions.

\section{Types of Interventions}

Studies that addressed strengthening of the scapulothoracic region, specifically the superficial back muscles as a primary intervention, in all settings (i.e. community and / or home settings) were included. These muscles include latissimus dorsi, levator scapula, rhomboid major, rhomboid minor, serratus anterior, pectoralis minor and upper, middle, and lower trapezius.

For the purposes of this review, scapulothoracic strengthening exercises were defined as "resistance-based exercises targeting the superficial back muscles." Studies solely focusing on postural-type strengthening were excluded.

Interventions that included additional therapies, such as stretching of the upper limb, chest, and scapula muscles were considered, but only accepted if the primary therapy was strength training. Co-intervention studies, such as those which incorporate physical 
therapy agents, manipulations, mobilisations, and pain science psychological therapy were also considered, but were only included provided they were done in conjunction with strength training. Each study included in this review was required to possess at least one training group with $a \geq 50 \%$ scapulothoracic-type training basis as identified across the numerous exercise regimes included in intervention populations described.

\section{Outcomes}

Any studies reporting outcomes related to neck function and pain were included regardless of the specific outcome measure used.

\section{Timeframe}

All studies which collected data immediately after the intervention, as well as during follow-up periods (i.e. 6 and / or 12 weeks post intervention) were included within this review.

\section{Information Sources}

A systematic search of four electronic databases, including Ovid Medline (1946 - 2019), Ovid Embase (1947- 2019), Scopus (1960 - 2019) and the Cochrane Library (1990 - 2019) was conducted. These databases have predominantly been utilised in recent published literature explored throughout preliminary research. Hence, these were considered applicable and predicted to capture the studies relevant to this topic as a result of their specific focus and inclusion of biomedically focused literature. The final search terms were verified by an academic librarian at the University of South Australia (15/03/19). Pearling reference lists of relevant and included studies was conducted to ensure no additional literature was excluded.

\section{Search Strategy}

Table 1 summarises the search terms and strategy applied to the Ovid Medline database. The strategy was altered appropriately with respect to variances in MeSH terms etc. across the Ovid Embase, Scopus and The Cochrane Library databases, prior to application.

Table 1: Search terms for primary search Ovid Medline database

\begin{tabular}{|c|l|}
\hline Row Number & Search terms \\
\hline 1 & $\begin{array}{l}\text { Neck/ } \\
\text { Neck muscles/ } \\
\text { Neck? or cervical or cervico* }\end{array}$ \\
\hline 2 & $\begin{array}{l}\text { Pain/ } \\
\text { Musculoskeletal pain/ } \\
\text { Nociceptive pain/ } \\
\text { Pain* or dysfunction* or patholog }{ }^{*} \text { or disorder? Or injur* }\end{array}$ \\
\hline 3 & $\begin{array}{l}\text { Neck pain/ } \\
\text { Neck ache? Or cervical pain? Or cervicalgia? Or cervicodynia? Or neck? Pain? Or neckache? }\end{array}$ \\
\hline 4 & $\begin{array}{l}\text { Superficial Back Muscles/ } \\
\text { Superficial back muscle* or trapezius* or rhomboid* or axioscapular or Serratus anterior or Levator } \\
\text { scapulae or Pectoralis minor } \\
\text { (Scapul* or upper extremit* } \\
\text { scapula dys }{ }^{*}\end{array}$ \\
\hline 5 & $\begin{array}{l}\text { exp exercise/ } \text { muscle? }^{*} \\
\text { exp exercise therapy/ } \\
\text { exp rehabilitation/ } \\
\text { exp resistance training/ } \\
\text { exp physical therapists/ } \\
\text { exercis* or rehab* or train* or therap* or physio* or strength* or SFT }\end{array}$ \\
\hline
\end{tabular}




\section{Combination of Search Terms}

Components within each row were combined with 'or'

Rows 1 and 2 were combined with 'and' and compared with row 3 with 'or'

Rows 4 and 5 and the above combination were combined with 'and'

Consistent with the topic of research and the variety of clinically applicable outcome measures, the search strategy did not include an outcome to maximise the volume of literature obtained during the initial stages of the search. Additionally, a comparator was not included in the search strategy, as the aim of this systematic review was to report the benefits and limitations of the clinical application of scapulothoracic strengthening exercises in individuals with neck pain. Searches were limited to the English language and human subjects only.

\section{Study Records \\ Data Management}

Two independent reviewers (GW, EW) uploaded search results from each electronic database into EndNote software, a cloudbased program utilised for storing and managing bibliographic references. ${ }^{11}$ The Endnote library was uploaded to Covidence. Covidence is a cloud-based platform that facilitates collaboration among reviewers during the study screening and selection process. ${ }^{12}$ This was used to screen the title and abstract screening of articles.

\section{Study Selection Processes}

Stage 1: Title and abstract screening was conducted by two independent reviewers (GW, EW) using Covidence, irrelevant articles were excluded. The inclusion and exclusion criteria were used to determine the inclusion of articles in the review. Stage 2: The articles were imported into Covidence and a full text screen of the articles were conducted by two reviewers (GW, EW) independently. Both reviewers read all articles in full and compared them to the inclusion and exclusion criteria to determine which articles were included in the systematic review. Reasons for exclusion were recorded. The selection process was also recorded and a PRISMA flow diagram was completed. Disagreements that couldn't be resolved by the two reviewers, were resolved by a third independent reviewer (LO).

\section{Data Collection Process}

A standardised data extraction form was developed by the review team and piloted independently by three independent reviewers on two of the included studies. Outcomes of the data extraction were compared by all reviewers for consistency. Using the standardised data extraction form, three reviewers (LO, HW, AZ) extracted data independently and in duplicate for each study included. To control for human error, the third impartial reviewer for each article adjudicated any unresolved disagreements and confirmed the data extraction process for each article.

\section{Data Items}

Using a standardised data extraction form, the following variables were collected: 1) participant characteristics including age, gender, country, setting, and stage of neck pain, 2) study design, 3) intervention characteristics including exercises, dosage, duration, frequency, muscles targeted, resistance, and progression, 4) comparator /control, 5) pain-based and other relevant outcome measures, 6) results, 7) authors conclusion, and 8) limitations.

\section{Methodological Quality \\ Critical Appraisal and Risk of Bias}

All papers selected for inclusion were assessed by six independent reviewers (LO, HW, GW, EW, AZ, LZ) for methodological quality and bias post-study inclusion. Consistent with the research question, purely quantitative studies were sought for inclusion. Specifically, the National Health and Medical Research Council (NHMRC) hierarchy of evidence was applied to determine the level of evidence of the included studies. ${ }^{13}$ Two reviewers (AZ, HW) allocated level of evidence, and a third reviewer was consulted in the event of disagreement (LO). All five included studies were classified as Intervention Level II Evidence: a randomised controlled trial. Subsequently, the PEDro tool was utilised in the evaluation of each article to verify methodological quality, using standardised instructions for administration accompanied by the tool. ${ }^{14}$ As highlighted by Maher and colleagues, the PEDro tool has satisfactory reliability for use in systematic reviews of physiotherapy RCTs. ${ }^{15}$ Refer to the "results" section for discussion of scores. All reviewers individually conducted critical appraisal of each study, compared results, and reached a general consensus on majority rules basis.

\section{Synthesis of Results}

Upon completion of the data extraction process, a meta-analysis was deemed inappropriate due to sufficient heterogeneity with respect to intervention and outcome measures, and lack of comparable statistics. Thus, extracted data was summarised in tabular form (Table 3 in Appendix) and synthesized in narrative form. Three independent reviewers (HW, AZ, LO) conducted this process. 


\section{RESULTS}

\section{Study}

Selection

The initial search identified 3,892 studies. Following pooling of the searches and removal of duplicates, 2,665 studies were screened for titles and abstracts. Thirty-nine (39) studies were reviewed in full, including 3 studies that were identified by Pearling. Of these studies, 5 successfully fulfilled the eligibility criteria. Although the vast majority of such studies made reference to the treatment of individuals with neck type pain/pathologies, researchers appeared to predominantly investigate the effectiveness of deep neck flexor (DNF) type exercises rather than scapulothoracic exercises. Hence, such articles were unable to satisfy the eligibility criteria for this systematic review. The authors of 2 studies were contacted in an attempt to obtain further detail regarding exercises included in intervention; however, failure to elicit a response occurred on both occasions, and thus studies were excluded. ${ }^{16,17}$ Figure 1 outlines the literature selection process.

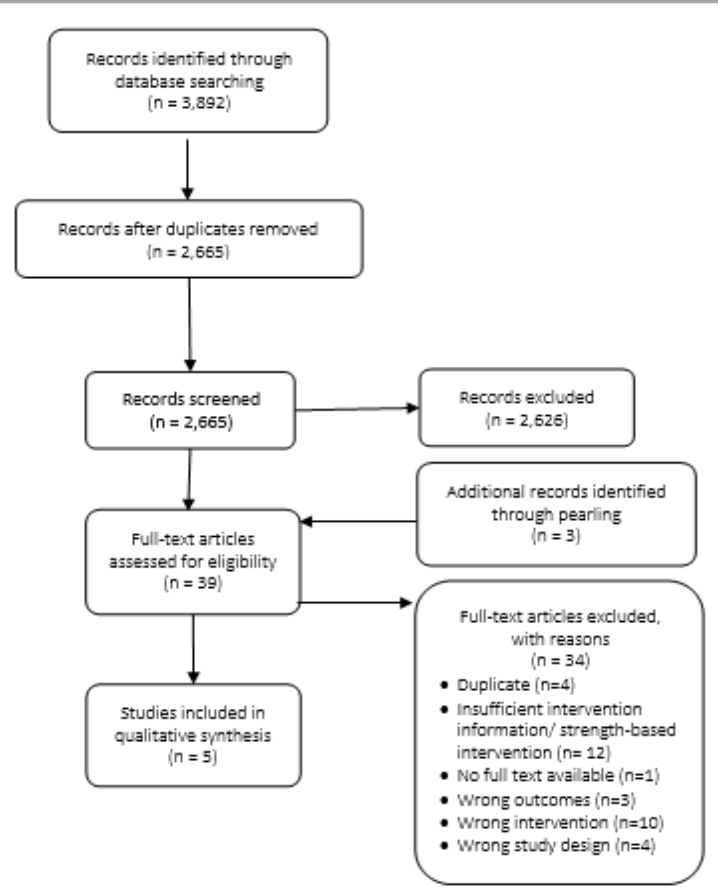

Figure 1. PRISMA Flowchart

\section{Study Characteristics}

Study characteristics are summarised in Table 3. All studies were RCTs, with participants from three countries identified: Denmark, Egypt, and Northern Sweden. ${ }^{18-22}$ All included studies were published between 1998 and 2016 and included baseline measurements identified prior to intervention, and later compared with those identified post intervention.

\section{Participants Characteristics}

The number of participants ranged from 42 to 103 with the mean age ranging from 38.20 to 48.83 years. More women than men were included in the trials, with 259 women and 70 men. Two of the trials included only office workers, the other three trials did not specify the occupation of the participants..$^{18-22}$

All of the trials selected participants with chronic neck pain; however, variation in regard to the diagnosis of neck pain was evident between trials. Andersen et al specified a diagnosis of trapezius myalgia defined by sustaining 1) chronic or frequent pain in the neck area, 2) tightness of the upper trapezius muscle, and 3) palpable tenderness of the upper trapezius muscle. ${ }^{18}$ Waling et al also specified chronic work-related trapezius myalgia, however, "work-related" was not defined..$^{22}$ Andersen et al used pain in neck / shoulders during the previous month of at least 3 on a $0-9$ scale..$^{19}$ Abdel-Aziem and Draz used neck pain for 6 weeks, and Randløv et al used participants who were suffering from chronic neck / shoulder pain for a minimum of 6 months. ${ }^{20,21}$

\section{Types of Intervention}

For the purposes of this review, studies were selected based on inclusion of at least one intervention group, comprising predominantly scapulothoracic-type strengthening exercises. Whilst all studies fulfilled this criterion, it should be noted that the composition of each scapulothoracic strengthening regime varied to a certain extent. 
The study conducted by Andersen et al used a combination of five dumbbell-resisted exercises in their specific strength training (SST) group. ${ }^{18}$ Unlike the other four studies included, these authors intentionally targeted the painful upper trapezius musculature, including 1-arm rows, shoulder abduction, shoulder elevation, reverse flyes, and upright rows. In comparison, Abdel-Aziem and Draz used a combination of body weight and gravity resisted exercises, which ultimately targeted the serratus anterior (push-up with a plus) and trapezius (horizontal shoulder abduction with scapular depression, adduction, and upward rotation in prone) musculature respectively. ${ }^{21}$ These exercises shared some similarity with those used by Andersen et al in 2014 who also included a "push-up plus" type exercise in prone, along with a "press-up" exercise, both utilising a combination of gravity and bodyweight to resist. ${ }^{19}$ Similar to Abdel-Aziem and Draz, these exercises were also designed to target the serratus anterior and trapezius musculature. ${ }^{21}$

The remaining two studies by Waling et al and Randløv et al shared some similarity in their scapulothoracic training groups. ${ }^{20,22}$ The triceps press in Waling and colleagues RCT, along with the arm abduction, push-away, push-ups, and neck flexion and extension exercises in Randløv and colleagues paper, were points of difference noted between the two programs. ${ }^{20,22}$ However, both included scapular retraction, shoulder flexion and latissimus pulldown type exercises. ${ }^{20,22}$

The authors of the included studies compared these scapulothoraci-type exercise groups with regimes summarised within the following titles:

Andersen et al 2008: General Fitness Training (GFT) and control groups (health education).

Andersen et al 2014: Control group (encouraged usual activity).

Abdel-aziem et al 2016: Physical Therapy Agents (PTA), and PTA plus DNF exercise groups.

Waling et al 2000: Endurance and Co-ordination training groups.

Randløv et al 1998: Nil comparison group included. Intervention groups varied on the basis of exercise intensity; one group was intensively trained, the other was lightly trained.

\section{Type of Outcomes}

The relevant outcome measures used in each study are displayed in Table 3. Three of the included studies used the visual analogue scale (VAS) as the main pain-related outcome measure.18,21,22 VAS is a subjective measure for participants to rate their pain, marked on a $0-10 \mathrm{~cm}$ (or $0-100 \mathrm{~mm}$ ) scale with 0 being "no pain" and 10 or 100 being "worst imaginable pain." Andersen et al used a self-rated pain intensity scale; participants subjectively rated their neck and shoulder pain on a scale of 0-9 with 0 being "no pain at all" and 9 being "worst possible pain."19 The VAS scale is considered the gold standard in measuring pain, with a high validity and reliability. ${ }^{23} \mathrm{Abdel}-\mathrm{Aziem}$ and Draz used the VAS scale and the neck disability index (NDI), which is a questionnaire designed to identify the impact of neck pain on activities of daily living (ADL). ${ }^{21}$ The NDI has 10 sections, with 6 items in each section. Each section is scored out of 5 (items ranging from completing the task with no problems, to not being able to complete the task at all).

Abdel-Aziem and Draz measured participants' cervical spine range of motion (ROM) in three planes using a universal goniometer and a double-armed full circle protractor to take the measurements. ${ }^{21}$ Randløv et al used a self-developed questionnaire evaluating the influence of neck pain on an individual's ability to participate in functional activities of daily living. ${ }^{20}$ This 10 -question scale was completed at baseline, after three months, after six months, and after twelve months which resulted in a total of 40 points.

Randløv et al also used two 11-point box scales which measured the patient's current pain and pain on average over the following 14 days, each totaling up to 20 points. ${ }^{20}$ Randløv et al measured maximum voluntary contraction (MVC) of cervical flexors and extensors using a strain gauge dynamometer. ${ }^{20}$ Participants sat on the dynamometer seat with their backs to the column to measure neck flexion, and then faced the opposite direction to measure neck extension. These measurements were performed with a starting position of 15 degrees flexion and were measured at $60 \%$ of the participants MVC. Results were measured in kiloponds and later converted to Newton-metres. All outcome measures were measured both before and after the total intervention study period.

\section{Methodological Quality/Risk of Bias}

The PEDro tool utilised in the process of critical appraisal has a scoring system where "Yes" $=1$ and "No" $=0$. The tool is scored on 11 criteria to provide a score out of 10 , with a score of $9-10$ considered excellent, 6-8 as good, 4-5 as fair, and 3 or below as poor methodological quality. Of the five included studies, $80 \%$ were considered 'good' quality and $20 \%$ were of 'fair' quality as demonstrated in Table 2. An important limitation to note is the lack of blinding of practitioners and assessors across the literature because of the use of physical interventions, therefore lowering the methodological quality. Trials were not excluded on the basis of quality. 
Table 2. Risk of bias for randomized controlled trials

\begin{tabular}{|c|c|c|c|c|c|c|c|c|c|c|c|c|c|}
\hline \multirow{2}{*}{ Study } & \multicolumn{11}{|c|}{ PEDro criteria } & \multirow{2}{*}{$\begin{array}{l}\text { PEDro } \\
\text { score }\end{array}$} & \multirow{2}{*}{$\begin{array}{l}\text { NHMRC Hierarchy of evidence } \\
\text { level }\end{array}$} \\
\hline & $1^{*}$ & 2 & 3 & 4 & 5 & 6 & 7 & 8 & 9 & 10 & 11 & & \\
\hline Andersen et al 2008 & + & + & + & + & - & - & - & + & + & + & + & 7 & Intervention study: level II \\
\hline Andersen et al 2014 & + & + & + & + & - & - & + & - & + & + & + & 7 & Intervention study: level II \\
\hline Abdel-Aziem \& Draz 2016 & + & + & + & + & - & - & + & + & + & + & + & 8 & Intervention study: level II \\
\hline Walinga et al 2000 & + & + & - & + & - & - & - & + & + & + & + & 6 & Intervention study: level II \\
\hline Randløv et al 1998 & + & + & + & + & - & - & - & - & - & + & + & 5 & Intervention study: level II \\
\hline
\end{tabular}

Legend: * In line with the PEDro marking criteria, criterion 1 was not included within the final PEDro score. ${ }^{14}$

\section{Results/Findings of Individual Studies}

The extracted data in Table 3 (see Appendix) summarises the characteristics and results of each included study.

\section{SYNTHESIS OF RESULTS/FINDINGS}

The following is a narrative extrapolation of the extracted data from the included studies.

\section{Scapulothoracic Strengthening Exercises vs. Control/Comparator}

Andersen et al (2008), Andersen et al (2014), and Waling et al all compared the effect of scapulothoracic type strengthening exercises with control and alternative forms of treatment such as leg bicycling, arm cycling, and body awareness training. ${ }^{18,19,22}$ Andersen et al reported significant changes in regards to pain, muscle activation and strength within a specific strength training (SST) exercise group incorporating scapulothoracic type exercises in comparison to general fitness training (GFT) and control type groups. ${ }^{18}$ No statistical significance or differences were found between the GFT and control groups. Data analysis revealed a $42 \%$ decrease in pain amongst the SST group before $(p=<0.05)$ and $49 \%$ after $(p=<0.01)$ completion of a dynamometer test. This trial suggests that SST can relieve neck pain, which in turn may increase the activity and strength of the painful trapezius muscles.

Similarly, Andersen et al (2014) compared the effect of scapular function training (SFT) exercises with a control group. ${ }^{19}$ Significant improvements in self-rated neck pain were reported amongst the SFT group $(p<0.01)$, supporting the findings of Andersen et al (2008). ${ }^{18}$ Further, a post hoc test showed a between group difference of 2.0 in self-rated neck pain ( $\left.95 \% \mathrm{Cl} 0.4-3.6\right)$. The inclusion of shoulder, neck and back ROM, as well as warm-up exercises in the SFT group suggests there may be some evidence that ROM and strength exercises can improve neck pain. In addition, a comparative analysis conducted by Waling et al found improvements in "pain in general" by $40-60 \%$ in all included participants. ${ }^{22}$ The VAS for "pain at worst" was significantly less between the strength and control group and between the endurance and control groups $(p=<0.05)$. Additionally, significantly larger reductions in pain on the VAS scale for "pain at present" $(p=<0.05)$ and "pain at worst" $(p=<0.05)$ were noted when the control group and experimental groups were compared. This suggests there is some evidence that training reduces the pain of work-related trapezius myalgia, however, whether this training should be strength, endurance or coordination training is unclear.

\section{Intensive vs Light Intensity Scapulothoracic and Cervical Strengthening Exercises}

Randløv et al investigated the clinical effectiveness of intensive vs light exercise programs incorporating scapulothoracic and cervical strengthening exercises. ${ }^{20}$ Significant improvements were reported with regards to objective parameters such as MVC of the cervical musculature in both the intensively trained group and the lightly trained group. Regarding pain score, a $20 \%$ and $25 \%$ reduction amongst the intensively trained group and the light trained group were reported respectively. The authors note that such improvements were lost at follow-up (6-12 months) for the light training group. However, a 6-month follow-up conducted in the intensively trained group revealed further reduction in pain to $33 \%$ over baseline values. A subsequent 12-month follow-up indicated a decline to $20 \%$ improvement over baseline within the intensively trained group. Despite such differences amongst 
groups, the authors were unable to report a statistically significant difference amongst groups at any time throughout the study ( $p=$ $0.07-0.99$ ). The changes in ADL questionnaire scores revealed that the light intensity group had a median improvement of $25 \%$ while the intensive group had a 38\% improvement. Improvements were sustained at follow-ups for both groups.

\section{Physical Therapy Agents (PTA) vs PTA Plus Exercises}

Abdel-Aziem and Draz studied three intervention clusters. ${ }^{21}$ Group 1's intervention was PTA, isometric stretching, and scapulothoracic exercises, group 2 included PTA only, and group 3 included PTA and DNF exercises. Groups 1 and 3 yielded significantly greater improvements in VAS scores following the 1-month intervention, in comparison to group $2(\mathrm{p}=0.001)$. At completion, improvements between groups 1 and 3 were similar, however, at the 3-month follow-up, VAS scores for group 3 were significantly lower than group $1(p=0.002)$. All groups yielded significant improvements in NDI scores at completion of the 1-month intervention. However, improvements were significantly greater in group 3 compared to groups 1 and 2 ( $p=0.001, p=0.030$ respectively). At the 3-month follow-up, only group 3 maintained NDI Improvements. Cervical ROM in the sagittal, transverse, and frontal planes improved significantly across all groups at completion of the 1-month trial. Measurements concerning the sagittal and transverse plane revealed significantly greater but similar improvements between groups 1 and 3 in comparison to group 2 at completion $(\mathrm{p}=0.001)$. These changes were sustained at follow-up. Regarding frontal plane ROM, improvements were significantly greater in groups 1 and 3 in comparison to group 2 at completion $(p=0.018)$, with group 3 sustaining significantly greater improvements in frontal plane ROM in comparison to groups 1 and 3 at follow-up. It should be noted that frontal plane ROM improvements were still sustained with significance 3 months post trial in group 1 , in comparison to group $2(p=0.001)$. This trial highlighted that a combination of DNF exercise with PTA's was the most effective regime for neck pain and dysfunction.

\section{DISCUSSION}

The aim of this systematic review was to establish the evidence behind the clinical application and effectiveness of scapulothoracic strengthening exercises to reduce neck pain. Despite limited evidence, the included studies were of moderate methodological quality, with all being RCTs. Sufficient heterogeneity with respect to outcome measures, baseline characteristics, and intervention programs, as well as a lack of detail provided in interventions, resulted in caution when interpreting results. The summarised findings from this systematic review indicate that scapulothoracic exercises may have a positive influence on subjective outcomes, such as pain, as well as objective measures, including strength and ROM. Despite the consistency of these positive results, the current evidence lacks regularity in terms of specific muscles targeted, and consequently execution of training including mode of exercise, intensity, duration, and progression. Thus, due to the ambiguous nature of findings collectively, caution should be sought by clinicians when applying scapulothoracic exercises to alleviate neck pain.

Most studies included either a physiotherapist or physical therapist present during intervention, otherwise it was not specified. $18-22$ Populations across the included studies similarly consisted of individuals with either trapezius myalgia, pain in the neck/shoulder region persisting for a minimum of three or six months or non-specific neck pain. ${ }^{18-22}$ Variation was present in regard to gender of participants, ranging from both female and male, only males or only females, with only slight variation in age across studies, ranging from means of 38.20 to 48.83 years of age. Thus, any connotations generated can be applied to a population of males or females, aged within approximately 38-48 years, with trapezius myalgia or chronic nonspecific pain in the neck/shoulder region.

\section{Types of Muscles Targeted}

Existing evidence has demonstrated effectiveness of targeted strength training of the painful muscles in alleviating neck pain; however, it has also been shown to cause an acute increase in pain. ${ }^{24}$ Particularly for patients who exhibit a compensatory pattern in the scapular muscles, exercises targeting selective activation of the weaker muscles with minimal activity of the hyperactive muscles have been suggested to alleviate neck pain. ${ }^{25,26}$ Four of the studies included in this review investigated this concept. Two studies used exercises targeting serratus anterior and lower trapezius as an intervention, one study targeted middle and lower trapezius, latissimus dorsi, rhomboids and muscles of shoulder flexion, and one study targeted middle trapezius, serratus anterior, deltoids, and muscles of neck flexion and extension. ${ }^{19-22}$ This variation in exercises makes it difficult to determine whether results can be attributed to targeting neck muscles, scapulothoracic muscles, or a combination thereof. The variability in the prescription of strength exercises may be explained by the absence of explicit guidelines on interventions for neck pain. Upon interpretation, it was apparent that three of these four studies used the VAS as the predominant outcome measure. Thus, statistical analysis was conducted to convert the "Self-Rated Pain Intensity" (SRPI) measure used in Andersen's study from the 10 point measure (scores of $0-9$ ) and approximate it against the 11 point VAS scores $(0-10)$ to an estimate of VAS values in order to allow comparison between studies. ${ }^{19} \mathrm{As}$ a result, each 1 point change in the SRPI was equivalent to a 1.1 point change in the VAS outcome measure. It could thus be deduced that collectively, all four of these studies showed findings of $12-38 \%$ change in pain scores over the course of the trial..$^{19-22}$ In contrast, one study used strengthening exercises targeting the deltoids and painful upper trapezius musculature as the intervention. ${ }^{18}$ VAS values in this study demonstrated a $42-49 \%$ change of pain. ${ }^{18}$ 


\section{Subjective and Objective Parameters}

Supplementary to pain, the included studies indicate short-term positive influences of scapulothoracic exercises across more functional outcome measures. One of the included studies comparing intense and light exercise regimes utilized an ADL questionnaire as a predominant outcome measure..$^{20}$ Upon analysis, a 20-30\% improvement at completion of intervention was established for both groups, which was maintained at six and twelve-months post intervention. ${ }^{20}$ Similarly, another included study investigating scapulothoracic exercises, PTA, and isometric stretching as one intervention employed the NDI as a measure of disability. ${ }^{21}$ Upon interpretation, a $12 \%$ improvement for this group was evident from baseline to one-month post intervention; however, the improvement was not maintained longer than one month. ${ }^{21}$ Although both outcome measures differ in obvious respects such as criteria and scoring systems, the two measures similarly address comparable components of functionality. Randløv's study utilizing the ADL questionnaire demonstrated greater improvements that were also maintained for longer duration. However, upon analysis, it was apparent that the outcome measure was based on a validated low back pain scale but had not undergone validation testing itself. ${ }^{20}$

Abdel-Aziem and Draz's study also included neck ROM as another complementary outcome measure. ${ }^{21} \mathrm{~A}$ significant increase in neck ROM was demonstrated in all three planes at one month and maintained at three months with minimal regression and range remaining significantly above baseline. ${ }^{21}$ At the three-month follow up, range in both sagittal and frontal planes demonstrated an increase of approximately fifteen degrees, with the largest improvement exhibited in the transverse plane. ${ }^{21}$ Thus, implicating scapulothoracic exercises, in combination with isometric stretching and PTA, have the greatest influence on neck rotation, an essential functional movement for daily life purposes. Other studies included in this review did not utilize neck ROM as a primary outcome measure, which limits full analysis. Similar to ROM however, Randløv's study comparing intensive and light exercise included strength as a functional outcome supplementary to pain. ${ }^{20}$ Upon analysis, it was evident that intense scapulothoracic exercises generated a $25 \%$ increase in maximal voluntary contraction for neck flexion and extension at the conclusion, indicating a significant improvement in functional ability. ${ }^{20}$ Although the means to directly compare homogeneous outcomes amongst the included studies is limited, it is still reasonable to suggest scapulothoracic exercises have positive influences on neck strength and ROM. These outcome measures, although not evaluated in all included studies, suggest that sequential to generalised pain reduction, scapulothoracic exercises may function in improving aspects of quality of life.

\section{Dosage}

Exercise dosage varied considerably across the included studies regarding the execution and time spent on strength exercises, warm-up, stretching and the use of combined modalities within interventions. Consequently, the ability to derive explicit recommendations for dosage is restricted. However, even if similarity existed, uncertainty may still be inherent. It should be noted that one of the studies failed to specify any detail regarding dosage of scapulothoracic exercises, limiting the ability to form any dosage-related recommendations on their specific intervention. ${ }^{21} \mathrm{~A}$ study investigating the dose-response of strengthening exercise for treatment of severe neck pain, suggests training at least 1-2 times weekly for a duration of 20 minutes to achieve optimum results for neck pain. ${ }^{27}$ All studies included in this review implemented strength training interventions between three to five times per week. This suggests that in terms of frequency, three to five times per week may be sufficient in generating improvements in some of the outcomes of interest. Duration of exercises across studies ranged from 20-90 minutes, with varying application of warm-up times and combination of other modalities. This variation in execution practices can suggest that scapulothoracic strength-type training programs of a minimum duration of 20 minutes may reduce neck pain should it be combined with a warm-up or stretching-type activity. Until further research is conducted, this combination may be considered an effective clinical application in the treatment of neck pain.

Intensity achieved using dumbbells, resistance bands, or air-machine resistance was usually an 8-12 repetition maximum with either 3 or 5 sets. One study specified varying training load according to the principle of periodization and progressive overload. ${ }^{19}$ The intervention varied from a 20-repetition maximum with 3 sets in the first week to a 10-repetition maximum with 5 sets in the final weeks. It would be of interest to conduct more trials evaluating this intervention design to thus make more explicit recommendations. All of the included studies implemented increasing resistance over time, excluding one study that did not specify any detail of progression. ${ }^{21}$ While the exact figures for repetitions and sets varied between articles, the consensus between the majority of included studies began with lower repetition, and progressed the repetitions until they could increase the resistance and return to their lower repetition threshold.

Only one of the included studies attempted to measure the effect of exercise dosage on outcomes by comparing intensive training and a light training programme. ${ }^{20}$ The study showed positive and lasting clinical gains for intensive exercise, however demonstrated no clinically significant difference between the intensive and light exercise groups, indicating that intensity is not an essential factor to consider in the conduction of exercise regimes. ${ }^{20}$ This was sought to be attributed to the lack of difference in intervention between groups. 


\section{Limitations}

As with any research, there are some limitations to this systematic review. Despite considerable searching of the literature, only five studies that met the inclusion criteria were able to be located. The search strategy was limited to reports published in English on human subjects. While the review included only RCTs, there were concerns regarding the methodological quality. The areas of concern included sampling techniques, diagnostic criteria of neck pain, execution of intervention, and lack of detail provided in intervention. In terms of execution of intervention, sufficient diversity existed in regard to muscles targeted, frequency, duration, intensity, and progression of exercises, with varying application of warm-up times and combination of other modalities. Variability in the prescription of exercises implemented in interventions made it difficult to attribute results to individual exercises.

Heterogeneity of outcome measures used amongst included studies was a predominant concern with regards to generating direct comparisons on subjective and objective parameters such as ADL function, neck strength, and ROM. The only consistent outcome measure was that of pain; however, statistical analysis was required to allow for comparisons between VAS and similar scales. Outcomes assessed in most of the studies included were only at baseline and at the conclusion, with one study including a follow up at six and twelve months and another including follow up at one month and at three months. ${ }^{20,21}$ This variation in follow up across studies consequently limited the ability to comment on long-term outcomes of the interventions. Lack of control groups in some studies, as well as limited differences between intervention groups, contribute to the difficulty in generating direct comparisons of results.

\section{CONCLUSION \\ Implications for Practice}

There is an increasing body of evidence to support the emerging concept that the implementation of scapulothoracic exercises may have a positive influence in outcomes such as neck pain. However, while scapulothoracic exercises may be considered in the management of neck pain, it must be acknowledged that there are several identified methodological concerns within the current evidence base. Thus, the ability to generate explicit recommendations regarding specific execution of exercises is limited. The current literature base is limited by considerable diversity in intervention and outcome measures and limited long-term follow up. However, with the limited evidence, scapulothoracic strengthening exercises could be considered in the treatment of neck pain. Scapulothoracic strength training may have positive impacts across subjective and objective parameters including pain, and sequentially ADL's, neck ROM, and strength. Based on collated findings, it is difficult to specify which scapulothoracic muscles should be targeted specifically; however, a 3-5 week program ranging from 20-90 minutes utilising dumbbells, resistance bands, or air-machine resistance with an 8-12 rep max across 3-5 sets may be considered appropriate for a neck pain population. This may be considered appropriate for a general neck pain population matching the inclusion criteria of this review. Furthermore, the principle of periodisation or progressive overload may be used based on individual presentations.

\section{Implications for Research}

An emerging body of evidence has been identified to support the use of scapulothoracic strengthening exercises in the treatment of neck pain. However significant methodological concerns have also been recognised, highlighting the need for future research. The significant heterogeneity of intervention parameters contributes to difficulty in ascertaining the most effective exercise program mode, intensity, and duration. Variation in combining exercise interventions with other modalities also existed. Thus, future research would benefit from studies implementing standardized intervention parameters. Further studies may improve on the current evidence by implementing a standardized outcome measure of pain, as well as long term follow up, to identify the sustainability and durability of results. Future research would also benefit from studies comparing exercises targeting painful upper trapezius and surrounding weaker muscles. It would also be beneficial to determine the effect of intensity of exercises, and the effect of including warm-up/stretching activities. A further implication for future research may relate to alternative interventions for neck pain, such as those described by Abdel-Aziem and Draz. ${ }^{21}$ While this study reported reduction in pain using scapulothoracic exercises combined with PTA, stronger findings were found amongst a comparative group implementing PTA with DNF exercises. This suggests that further comparison of scapulothoracic type exercises and DNF exercises should be investigated.

\section{Funding:}

No funding was received to complete this systematic review.

\section{REFERENCES}

1. Hoy D, March L, Woolf A, Blyth F, Brooks P, Smith E, Vos T, Barendregt J, Blore J, Murray C, Burstein R. The global burden of neck pain: estimates from the global burden of disease 2010 study. Ann Rheum Dis. 2014;73(7):1309-1315.

2. Hoy DG, Protani M, De R, Buchbinder R. 2010, The epidemiology of neck pain. Best Pract Res Clin Rheumatol. 2010;24(6):783-792. 
3. March L, Smith EU, Hoy DG, Cross MJ, Sanchez-Riera L, Blyth F, Buchbinder R, Vos T, Woolf AD. Burden of disability due to musculoskeletal (MSK) disorder. Best Pract Res Clin Rheumatol. 2014;(3):353-366.

4. Childs J, Cleland J, Elliott J, Teyhen D, Wainner R, Whitman J, Sopky B, Godges J, Flynn T, Delitto A, Dyriw G. Neck pain: clinical practice guidelines linked to the International Classification of Functioning, Disability, and Health from the Orthopaedic Section of the American Physical Therapy Association. JOSPT. 2008;38(9):A1-A34.

5. Carpenter D, Nelson B. Low back strengthening for the prevention and treatment of low back pain. Medicine and Science in Sports and Exercise. 1999;31(12):18-24.

6. Koltyn K, Arbogast R. Perception of pain after resistance exercise. Br J Sports Med. 1998;32(1):20-24.

7. Thorén P, Floras J, Hoffmann P, Seals D. Endorphins and exercise: physiological mechanisms and clinical implications. Medicine and Science in Sports and Exercise. 1990;22(4):417-428.

8. Falla D, Bilenkij G, Jull G. Patients with chronic neck pain demonstrate altered patterns of muscle activation during performance of a functional upper limb task. Spine. 2004;29(13):1436-1440.

9. Wegner S, Jull G, O'Leary S, Johnston V. The effect of a scapular postural correction strategy on trapezius activity in patients with neck pain. Man Ther. 2010;5(6):62-566.

10. Knežević O, Mirkov, D. Trunk muscle activation patterns in subjects with low back pain. Vojnosanit Pregl (Military Medical Review [Croatia]). 2013;70(3):315-318.

11. University of South Australia 2019, Library Guides, Endnote, University of South Australia, viewed 15th March 2019, <https://guides.library.unisa.edu.au/endnote>

12. Covidence 2019, Covidence, viewed 15th March 2019, <https://www.covidence.org/home>

13. Australian Government 2009, NHMRC additional levels of evidence and grades for recommendations for developers of guidelines, The National Health and Medical Research Council, viewed 12 March 2018, <https://www.nhmrc.gov.au/_files_nhmrc/file/guidelines/developers/nhmrc_levels_grades_evidence_120423.pdf>

14. PEDro 1999, PEDro scale, PEDro Physiotherapy Evidence Database, viewed 8 March 2019, <https://www.pedro.org.au/wpcontent/uploads/PEDro_scale.pdf>.

15. Maher C, Sherrington C, Herbert R, Mosely A, Elkins M. Reliability of the PEDro Scale for rating quality of randomized controlled trials. Phys Ther. 2003;83(8):713-721.

16. Andersen C, Andersen L, Gram B, Pedersen M, Mortensen O, Zebis M, Sjøgaard G. Influence of frequency and duration of strength training for effective management of neck and shoulder pain: A randomised controlled trial. $\mathrm{Br} J$ Sports Med. 2012;46(14):1004-1010. https://doi.org/10.1136/bjsports-2011-090813

17. Zebis M, Andersen L, Pedersen MT, Mortensen P, Andersen CH, Pedersen MM, Boysen M, Roessler K, Hannerz H, Mortensen OS, Sjøgaard G. Implementation of neck/shoulder exercises for pain relief among industrial workers: A randomized controlled trial. BMC Musculoskelet Disord. 2011;12:205. doi: https://doi.org/10.1186/1471-2474-12-205

18. Andersen L, Andersen C, Zebis M, Nielsen P, Søgaard K, Sjøgaard G. Effect of physical training on function of chronically painful muscles: A randomized controlled trial. J Appl Physiol. 2008;105 6):1796-1801.

19. Andersen C, Andersen L, Zebis M, Sjøgaard, G. Effect of scapular function training on chronic pain in the neck/shoulder region: A randomized controlled trial. J Occup Rehabil. 2014;24(2):316-324.

20. Randløv A, Manniche C, Kryger P, Jordan A, Holm B. Intensive dynamic training for females with chronic neck/shoulder pain. A randomized controlled trial. Clin Rehabil. 1998;12(3):200-210.

21. Abdel-Aziem A, Draz A. Boyun agrisinda derin boyun fleksor egzersizinin etkinligi: randomize kontrollu calisma (Efficacy of deep neck flexor exercise for neck pain: a randomized controlled study). Turk J Phys Med Rehabil. 2016;62(2):107-115.

22. Waling K, Sundelin G, Ahlgren C, Järvholm B. Perceived pain before and after three exercise programs - a controlled clinical trial of women with work-related trapezius myalgia. Pain. 2000;85(12):01-207.

23. Yarnitsky D, Sprecher E, Zaslansky R, Hemli J. Multiple session experimental pain measurement. Pain.1996;67(2-3):327333. https://www.ncbi.nlm.nih.gov/pubmed/8951926

24. Andersen L, Kjaer M, Sogaard K, Hansen L, Kryger A, Sjøgaard, G. Effect of two contrasting types of physical exercise on chronic neck muscle pain. Arthritis Rheum. 2008;59(1):84-91.

25. Cools AM, Dewitte V, Lanszweert F, Notebaert D, Roets A, Soetens B, Cagnie B, Witvrouw EE. Rehabilitation of scapular muscle balance: Which exercises to prescribe? Am J Sports Med. 2007;35(10):1744-1751.

26. Ellenbecker T, Cools A. Rehabilitation of shoulder impingement syndrome and rotator cuff injuries: An evidence-based review. (Report). Br J Sports Med. 2010;44(4)319-327.

27. Andersen CH, Andersen LL, Pedersen MT, Mortensen P, Karstad K, Mortensen OS, Zebis MK, \& Sjøgaard G. Doseresponse of strengthening exercise for treatment of severe neck pain in women. J Strength Cond Res. 2013;27(12):33223328. 


\section{APPENDIX}

Table 3. Characteristics and results of each included study

\begin{tabular}{|c|c|c|c|c|}
\hline $\begin{array}{l}\text { Author \& } \\
\text { Year }\end{array}$ & $\begin{array}{l}\text { PEDro } \\
\text { Score }\end{array}$ & Participants & Intervention & Control/Alternative Intervention \\
\hline $\begin{array}{l}\text { Andersen } \\
\text { et al } 2008\end{array}$ & $7 / 10$ & $\begin{array}{l}\text { Denmark, } 42 \\
\text { women - chronic/ } \\
\text { frequent neck pain } \\
\& \text { diagnosis of } \\
\text { trapezius myalgia } \\
\text { Mean age = } 44 \text { y.o. }\end{array}$ & $\begin{array}{l}\text { 10-week intervention } \\
\text { SST: } 20 \text { min sessions } 3 \text { x a wk; 8-12 } \\
\text { reps of } 3 \text { of; } 1 \text {-arm row, shoulder abd, } \\
\text { shoulder elevation, reverse flyes \& } \\
\text { upright row. }\end{array}$ & $\begin{array}{l}\text { GFT: Leg bicycling at } 50-70 \% \text { max. } \\
\text { oxygen uptake for } 20 \text { mins, } 3 \text { x a } \\
\text { wk. } \\
\text { Control: no exercise (health } \\
\text { promoting information activities } \\
\text { provided once a wk). }\end{array}$ \\
\hline $\begin{array}{l}\text { Andersen } \\
\text { et al } 2014\end{array}$ & $7 / 10$ & $\begin{array}{l}\text { Denmark, } 37 \\
\text { women \& } 10 \text { men - } \\
\text { chronic non-specific } \\
\text { pain in the } \\
\text { neck/shoulder } \\
\text { region } \\
\text { Mean age }=44 \text { y.o. }\end{array}$ & $\begin{array}{l}\text { 10-week intervention } \\
\text { SFT: } 20 \text { min sessions, } 3 \text { x a wk. Short } \\
\text { warm up - slowly moving neck, upper } \\
\text { back, shoulder blades } \& \text { shoulder } \\
\text { joint through pain-free ROM. } 3 \times 10 \text { of - } \\
\text { press-ups \& push-up plus' in } \\
\text { beginning wks } \rightarrow 5 \times 10 \text { in final wks. }\end{array}$ & $\begin{array}{l}\text { Control: Was not offered any } \\
\text { physical training but encouraged to } \\
\text { stay active as usual. }\end{array}$ \\
\hline $\begin{array}{l}\text { Waling et } \\
\text { al } 2000\end{array}$ & $6 / 10$ & $\begin{array}{l}\text { Northern Sweden, } \\
103 \text { women - } \\
\text { chronic work-related } \\
\text { trapezius myalgia } \\
\text { Mean age }=38.2 \\
\text { y.o. }\end{array}$ & $\begin{array}{l}\text { 10-week intervention } \\
\text { Strength: } 1 \text {-hour sessions; } 3 \text { x a wk; } \\
10 \text { min warm-up, } 3 \times 10-12 \text { max } \\
\text { voluntary contractions; lat pulldowns, } \\
\text { triceps press, shoulder flex \& scap } \\
\text { retraction, } 10 \text { min stretching cool- } \\
\text { down. }\end{array}$ & $\begin{array}{l}\text { Endurance: } 3 \times \text { a wk; } 3 \text { mins arm } \\
\text { cycling on ergometer alternating } \\
\text { with } 30 \text { reps of arm exercises with } \\
\text { rubber expanders \& abdominal \& } \\
\text { back exercises. } \\
\text { Coordination: } 3 \text { x a wk of 'body } \\
\text { awareness training'. } \\
\text { Control: no physical training; 2-hour } \\
\text { sessions } 1 \text { x a wk of stress } \\
\text { management. }\end{array}$ \\
\hline $\begin{array}{l}\text { Abdel- } \\
\text { Aziem \& } \\
\text { Draz } \\
2016\end{array}$ & $8 / 10$ & $\begin{array}{l}\text { Egypt, } \\
60 \text { men - neck } \\
\text { pain for } \geq 6 \text { wks } \\
\text { Mean age }=48.83 \\
\text { y.o. }\end{array}$ & 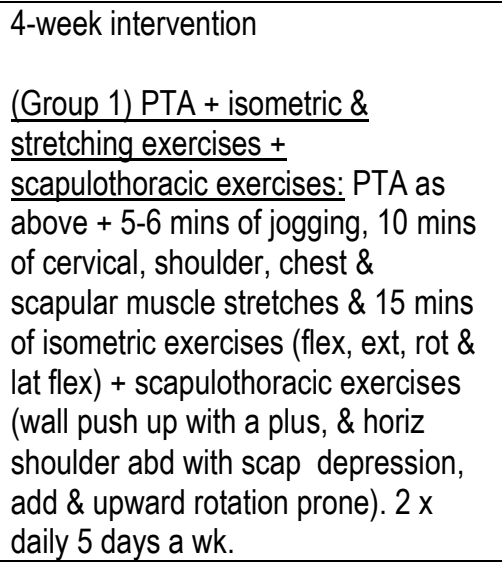 & $\begin{array}{l}\text { (Group 2) PTA: Infrared irradiation } \\
\text { (20 mins, R } 125,250 \text { watts), TENS } \\
(30 \text { mins, } 80 \mathrm{~Hz}, 10-30 \mathrm{~mA}), \\
\text { continuous ultrasound (1.5 W/cm2, } \\
1 \mathrm{MHz} \text { for } 10 \text { mins). } 2 \text { x a day, } 5 \\
\text { days a wk. } \\
\text { (Group 3) PTA + DNF exercise: PTA } \\
\text { as above + DNF exercises; } 10 \times 10 \\
\text { sec head nod hold to flatten curve of } \\
\text { neck in supine. } 2 \times \text { daily, } 5 \text { days a wk. }\end{array}$ \\
\hline $\begin{array}{l}\text { Randløv } \\
\text { et al } 1998\end{array}$ & $5 / 10$ & $\begin{array}{l}\text { Denmark, } 77 \\
\text { females - chronic } \\
\text { neck pain } \\
\text { Mean age }=39\end{array}$ & $\begin{array}{l}\text { 3-month intervention } \\
\text { ITP: approx. 1.5-hour sessions; } 3 \text { x } \\
\text { wk; } 10 \text { mins of bicycling \& stretching } \\
\text { of relevant muscle groups. } 5 \times 20 \text { of; } \\
\text { arm Abd, shoulder retraction, arm } \\
\text { swing, neck ext, neck flex, push up \& } \\
\text { pull down. }\end{array}$ & $\begin{array}{l}\text { LTP: approx. 1.5-hour sessions; } 3 x \\
\text { a wk; } 14 \text { mins of hot packs, } 15 \text { mins } \\
\text { of stationary bicycling \& stretching } \\
\text { of relevant muscle groups \& } 20 \text { reps } \\
\text { of; arm Abd, shoulder retraction, } \\
\text { arm swing, neck ext, neck flex \& } \\
\text { push-away. }\end{array}$ \\
\hline
\end{tabular}


Table 3. Characteristics and results of each included study (cont.)

\begin{tabular}{|c|c|c|c|c|c|}
\hline $\begin{array}{l}\text { Author \& } \\
\text { Year }\end{array}$ & $\begin{array}{l}\text { Follow } \\
\text { up }\end{array}$ & Outcome & $\begin{array}{l}\text { Outcome } \\
\text { measures }\end{array}$ & Short term (post-intervention) & Long term (follow-ups) \\
\hline $\begin{array}{l}\text { Andersen } \\
\text { et al } \\
2008\end{array}$ & $\mathrm{~N} / \mathrm{A}$ & Pain & VAS & $\begin{array}{l}\text { A decrease in SST group both } \\
\text { before }(42 \% ; P<0.05) \& \text { after the } \\
\text { dynamometer test }(49 \% ; P<0.01) \\
\text { from pre- to post intervention was } \\
\text { found. No significant difference } \\
\text { found in GFT \& control groups. }\end{array}$ & $\mathrm{N} / \mathrm{A}$ \\
\hline $\begin{array}{l}\text { Andersen } \\
\text { et al } \\
2014\end{array}$ & $\mathrm{~N} / \mathrm{A}$ & Pain & $\begin{array}{l}\text { Self-Rated } \\
\text { Pain } \\
\text { Intensity (in } \\
\text { the neck \& } \\
\text { shoulder area) }\end{array}$ & $\begin{array}{l}\text { A significant change in self-rated } \\
\text { pain between SFT group \& control } \\
\text { group ( } p<0.01 \text { ) was found. A } \\
\text { between group difference of } 2.0 \\
(95 \% \mathrm{Cl} 0.4-3.6 \text { ) was reported. }\end{array}$ & $\mathrm{N} / \mathrm{A}$ \\
\hline $\begin{array}{l}\text { Waling et } \\
\text { al } 2000\end{array}$ & $\mathrm{~N} / \mathrm{A}$ & Pain & $\begin{array}{l}\text { VAS scale } \\
(0-10 \mathrm{~mm})\end{array}$ & $\begin{array}{l}\text { Reduction of } 10 \mathrm{~mm} \text { of "pain in } \\
\text { general" was reported by } 40-60 \% \\
\text { of the participants in all groups. } \\
\text { VAS "pain at worst" was less } \\
\text { between the Strength \& Control } \\
\text { group }(P=<0.05) \text {. Larger } \\
\text { reductions in pain for "pain at } \\
\text { present" }(P<0.05) \text { \& "pain at } \\
\text { worst" }(P=<0.05) \text { in all groups. }\end{array}$ & $\mathrm{N} / \mathrm{A}$ \\
\hline $\begin{array}{l}\text { Abdel- } \\
\text { Aziem \& } \\
\text { Draz } \\
2016\end{array}$ & $\begin{array}{l}1 \text { and } \\
3 \\
\text { months }\end{array}$ & $\begin{array}{l}\text { Pain } \\
\text { Function }\end{array}$ & $\begin{array}{l}\text { (1) VAS } \\
\text { (2) Neck } \\
\text { disability } \\
\text { index (NDI) } \\
\text { questionnaire } \\
\text { (3) ROM of the } \\
\text { neck in three } \\
\text { planes }\end{array}$ & $\begin{array}{l}\text { Significant decrease of VAS score } \\
\text { in all groups after intervention. } \\
\text { Decrease of groups } 1 \text { and } 3 \text { were } \\
\text { significantly lower than group } 2 \text { ( } p= \\
0.001) \text {, but no significant } \\
\text { differences between groups } 1 \text { and } \\
3 \text { ( } P=0.191) \text {. } \\
\text { Significant decrease of NDI scores } \\
\text { after intervention- group } 3 \text { was } \\
\text { significantly lower than group } 1 \\
\text { and group } 2 \text { ( } P=0.030, p=0.001) \\
\text { with no significant difference } \\
\text { between group } 1 \text { and } 2 \text { ( } P=0.259) \text {. }\end{array}$ & $\begin{array}{l}\text { Improvements of group } 3 \text { at } 3 \\
\text { months were higher than } \\
\text { group } 1 \text { and } 2(p=0.030) \text {. } \\
\text { Sagittal and transverse } \\
\text { planes showed } \uparrow \text { in ROM in } \\
\text { both follow up periods } \\
\text { ( } p=0.001), \text { but group } 2 \text { was } \\
\text { lower ( } p=0.001) \text {, with no } \\
\text { significance difference } \\
\text { between groups } 1 \text { and } 3 \\
\text { ( } p=0.616, p=0.577, p=0.768 \\
\text { and } p=0.080) . \text { Frontal planes } \\
\uparrow \text { in group } 1 \text { and } 3 \\
\text { significantly higher than } \\
\text { group } 2 \text { ( } p=0.018) \text {. No } \\
\text { significant difference between } \\
\text { group } 1 \text { or } 3 \text { ( } p=0.529) \text {. }\end{array}$ \\
\hline $\begin{array}{l}\text { Randløv } \\
\text { et al } \\
1998\end{array}$ & $\begin{array}{l}6 \& 12 \\
\text { months }\end{array}$ & $\begin{array}{l}\text { Pain } \\
\text { Function } \\
\text { Function }\end{array}$ & $\begin{array}{l}\text { 1) 11-point } \\
\text { box scale for } \\
\text { pain } \\
\text { (2) MVC of } \\
\text { cervical flex } \\
\text { \& ext (Nm) } \\
\text { (3) ADL } \\
\text { Questionnaire }\end{array}$ & $\begin{array}{l}\text { Pain decreased by } 25 \% \text { in the LTP } \\
\text { and } 20 \% \text { in the ITP at conclusion. } \\
\text { Both groups improved significantly } \\
\text { in objective parameters (MVC) } \\
\text { following training. } \\
\text { Light group: ADL scores } \uparrow \text { by } 25 \% \\
\text { Intense group: ADL scores } \uparrow \text { by } \\
38 \% \text {. }\end{array}$ & $\begin{array}{l}\text { Both groups scores were } \\
\text { maintained at follow-ups. }\end{array}$ \\
\hline
\end{tabular}

Abbreviations: abd = abduction, add = adduction, $\mathrm{ADL}=$ activities of daily living, $\mathrm{DNF}=$ deep neck flexor exercises, ext = extension, flex = flexion, GFT = general fitness training, ITP = intensive training program, lat = latissimus, LTP = light training program, MVC= maximal voluntary contraction, $\mathrm{PTA}=$ physical therapy agents, $\mathrm{ROM}=$ range of motion, scap $=$ scapular, $\mathrm{SFT}=$ Scapular function training, SST = specific strength training, TENS= transcutaneous electrical nerve stimulation, VAS= visual analogue scale, $\uparrow=$ improved/increased. 